\title{
Development, Implementation, and Effectiveness Analysis of an Online Course With Intensive Technical Contents
}

\author{
Julie Zhang, Ali Kashef, Farah Kashef \\ University of Northern Iowa, Cedar Falls, USA
}

\begin{abstract}
Industries' demand for sufficiently trained engineers and technologists is increasing in order to remain competitive in manufacturing globalization. The development of educational technologies powered by high-speed computers and networks has enabled many universities to offer online and hybrid courses/programs to accommodate the educational needs. However, there is still a challenge to provide quality teaching and effectiveness when courses containing intensive technical contents are offered online. With support from different departments at the University of Northern Iowa (UNI), the course TECH 3142 Statistical Quality Control (TECH 3142), which intensively involves statistical calculation, reasoning, and software demonstration, was developed and delivered online by applying Quality Matters' (QM) online course quality assurance principles. Analyzing the qualitative and quantitative data collected, this paper presents a case study on the development, implementation, and student learning effectiveness evaluation for TECH 3142 online course with comparison to the face-to-face instruction. The experience shared in the paper may bring references to the distance learning community to improve the quality of online courses.
\end{abstract}

Keywords: online education/distance learning, technology/engineering education, online course development and assessment, Quality Matters (QM)

\section{Introduction}

To remain competitive in manufacturing globalization, the United States of America (the U.S. or USA) industries have innovated and implemented advanced technologies, such as computer numerical control (CNC) machine tools, robotics, and others to control and monitor manufacturing production. Accompanying with rapid technological changes, the workforce with sufficiently trained knowledge is in high demand in the U.S. job market (The U.S. Department of Labor, 2010). To accommodate the educational needs for more and well-trained managers, engineers, technologists, etc., many universities have added online and hybrid courses/degree programs, in addition to the traditional face-to-face teaching. The advances of educational technologies, mainly powered and driven by the high-speed personal computers and networks, make it possible for students to have flexibility and complete studies at their own pace through distance learning.

Despite the success of online education in many disciplines, there is still a challenge to offer online courses when the courses have rigorous technical contents, such as subjects related to math and sciences, where the face-to-face teaching shows more advantages in easy interaction to clarify confusions and questions

Julie Zhang, Ph.D., association professor, Department of Technology, University of Northern Iowa. 
(Aichouni, Benchicou, \& Nehari, 2013). Can such type of courses be developed and effectively delivered through online education? What educational technologies are needed in order to offer an online course with equivalent qualities of its face-to-face version? How can the effectiveness of an online course with intensive technical contents be assessed? This paper intended to answer these questions by presenting a case study of developing and delivering an online course at the University of Northern Iowa (UNI), which includes intensive technical contents, along with its effectiveness evaluation through comparing a course that was taught in the traditional face-to-face method by the same instructor.

\section{Literature Review}

Education plays a key role in preparing the workforce with skills that meet the industries' needs. Due to the constraints of the regular meeting hours and locations, distance learning originally started as correspondence courses back in the late 1800s (Caruth \& Caruth, 2013). At that time, there were no supporting audio and video, and distance learning therefore through correspondence format could be very difficult. In the 1980s and 1990s, when videocassette recorder (VCR) was popular, many universities offered distance learning courses via capturing lecture videos in VCR tapes and then mailing them to students. The effectiveness of distance learning improved, but the learners' schedule normally was late at least one week compared to the onsite students. In the recent decade, increasing uses of high-speed computers and Internet enabled online education as a proper teaching method. Conducting consecutive surveys annually since 2006, the Sloan Consortium reported that the online enrollment growth rate in 2014 was $6.1 \%$, which was the lowest in the survey series (Allen \& Seaman, 2014).

\section{Benefits of Online Education}

Online education can provide time and location flexibility (Bourne, Harris, \& Mayadas, 2005). This can be an important motivation for professionals who want to advance their knowledge and career by taking e-learning lessons in convenient time. One attraction of online education is its cost savings, which includes costs related to travelling in addition to the room and board charges (Welsh, Wanberg, Brown, \& Simmering, 2003). Another benefit is that e-learning powered by the Internet technology allows unlimited access to electronic resources, and students can study and review the learning materials on their own pace.

\section{Unique Requirements of Distance Learning for Technology/Engineering Courses}

The online courses and programs related to engineering and technology disciplines display a similar growing trend. While the advanced educational technology makes it promising, there are some disadvantages, especially for subjects in engineering and technology fields. The lack of interactions among student peers and instructors is a concern in online courses (Kinney, Liu, \& Thornton, 2012). Competencies, such as analytical skills and logical thinking in technical fields, cannot be solidly established unless a lot of problem solving examples are demonstrated, discussed, and practiced, all of which require interactions. If an online course is not designed and taught properly, the non-interactive learning environment can make students feel isolated or even fail in the end (Peerani, 2013). One hurdle for online courses in technical fields is that the lab components are hard to be included. The recent development of educational technologies improved this situation. For example, Astatke, Scott, Connor, and Ladeji-Osias (2012) reported a case where a sophomore level Electronic Engineering course was successfully delivered completely online. This case study also presented on how Adobe Connect was used so that students could demonstrate their design and laboratory experiment circuit from a remote desk. 


\section{Assessment of Online Course and Student Outcomes}

The literature on assessment of online course and student outcomes shows varied results in different types of educational institutions. Studies found that students who took online course at community colleges had a lower performance on average. Xu and Jaggars $(2011 ; 2013$; 2014) and Hart, Friedmann and Hill (2015) conducted separate studies in community colleges in Virginia and California and they found similar results that students enrolled in online courses performed not well as compared to their peers in face-to-face courses. On the other hand, there are also studies at four-year colleges reporting no or few differences in student performance in the two different delivery formats. Stack (2015) reported a test of 64 students enrolled in criminology classes in online and face-to-face format at a Carnegie research extensive university and there was no difference in the exam scores and concluded that the academic performance of online students was the same as that of traditional classes. The University of Massachusetts Amherst carried out a pilot comparative learning outcomes study with the instructors who taught an online and face-to-face version of the sane course (Stassen, Blaustein, Rogers, \& Shih, 2007). Only one statistically significant result emerged among a long list of individual ratings and performances. With their findings, this report generally supported that there were few differences in student learning outcomes across the two instructional modes. Although teaching delivery is an important factor, the student learning outcomes can be impacted by many factors. For example, students' academic background, self-control, and self-motivation could affect the outcome significantly. A shared conclusion from the above reviewed studies is that online course student learning outcome is a complex phenomenon and the student outcome assessment should be more specific, and a general conclusion may not be helpful.

\section{Quality Matters (QM) Program}

QM is a nationally-known quality assurance program using peer review process to assure the quality and continuous improvement of online education (Quality Matters, 2015). To be certified, the instructor must attend the QM professional development workshop and the online course developed must achieve 81 out of 95 possible points. In addition, the course must meet all the essential criteria according to QM's rubrics. Ralston-Berg (2014) conducted a survey to investigate the value of QM's rubrics from students' view and this study found that all QM rubric items were ranked important by students, although there were some differences between the students' perception and QM-assigned values.

\section{Online Course Development for TECH 3142 Statistical Quality Control (TECH 3142)}

The UNI, one of the three public universities in the State of Iowa, has invested a great amount of resources in online education programs, such as educational technologies, professional training, and technical support. Due to its outstanding work, the Continuing and Distance Education achieved a series awards and recognitions: Having been recognized within the 100 best online colleges in the U.S. (Affordable College Online, 2015) and ranked No. 1 among the state's public universities and colleges for an exceptional collection of high-quality, flexible distance learning options at a very affordable price. As of 2016, United News of India (UNI) offers three bachelor level undergraduate degree programs, 24 master level graduate degree programs as well as 12 endorsements/certificates and professional development programs.

As mentioned earlier, the QM is a nationally recognized quality assurance program for online and blended courses (Quality Matters, 2015) and many universities in the U.S. have adopted QM's principles in variety of 
online programs (Goodson, Miertschin, \& Stewart, 2011; Young, 2014). Continuing and Distance Education in UNI has adopted QM's rubric of standards for all online course design on campus. Essential to the successful implementation of the QM initiative are its professional development opportunities. To begin with the process, faculty members must participate in the workshop and receive the QM training certificate.

Located in one of the manufacturing industry clusters in Iowa, UNI has established a long-term and interactive relationship with the local industries through specialized training and technology transfer, small business counseling, market research and analysis, and hands-on innovative educational and technical advice. Offering six technology related undergraduate degree programs along with the graduate programs, the Department of Technology provides a skilled pool of workforce for the local industries. With many representatives from these industries seating in the department advisory board and seeing the need of online education opportunity for nontraditional students from working professionals, the department started to offer the Technology Management Bachelor of Art (B.A.) online cohort program in 2014. The program is concerned with the field of supervision and management of personnel and resources across the technical spectrum and wide variety of complex technological systems, aiming at preparing management-oriented technical professionals for careers in good producing industries and related technical service areas. The program provides instruction in production and operations management, project management, computer applications, quality control, safety and health issues, statistics, and general management principles. Key competencies required by the industries cannot be built without courses dealing with intensive technical contents. TECH 3142 in the Technology Management B.A. program is presented in this case study.

TECH 3142 is a required technical course for the Technology Management B.A. program, focusing on the application of probability, sampling techniques, and other statistical concepts to control and enhance quality in both manufacturing and service industries. Different from other online courses, which most deal with reading, writing, and discussion tasks, TECH 3142 has more technical contents using math, statistics, and computer software skills. The instructor has been teaching the face-to-face class for many years. With the experiences learned from classroom teaching, the rubrics learned in the QM workshop for online courses, and the help provided by the Continuing and Distance Education team and Instructional Design and Technology team, the instructor developed online course materials for TECH 3142 in summer 2014 by following the QM rubrics.

To ensure that all the rubrics are met in TECH 3142 online course development, the course syllabus must be reviewed by the Instructional Design and Educational Technology team on campus. From the point of view of curriculum and instruction, the review attention was particularly put on developing measurable learning objectives, as well as how learning objectives and assessment strategies were aligned together in the course syllabus and all lessons. The course syllabus must also include clear statements on how the course delivery technology is provided by the university, and how the students are expected to prepare their corresponding technology (such as computer, software, web camera, microphone, etc.) at home. The syllabus must include necessary technical support information that is provided by the university in case students need assistances in accessing to the learning materials.

Once, the syllabus as guideline was finalized, it was the instructor's task to realize these learning objectives through designing specific contents, such as lectures, assignments, and tests. Figure1 shows the very first interface for TECH 3142 online course to process with "START HERE," and Figure 2 shows the screen shot of course contents that is located in the first week. 


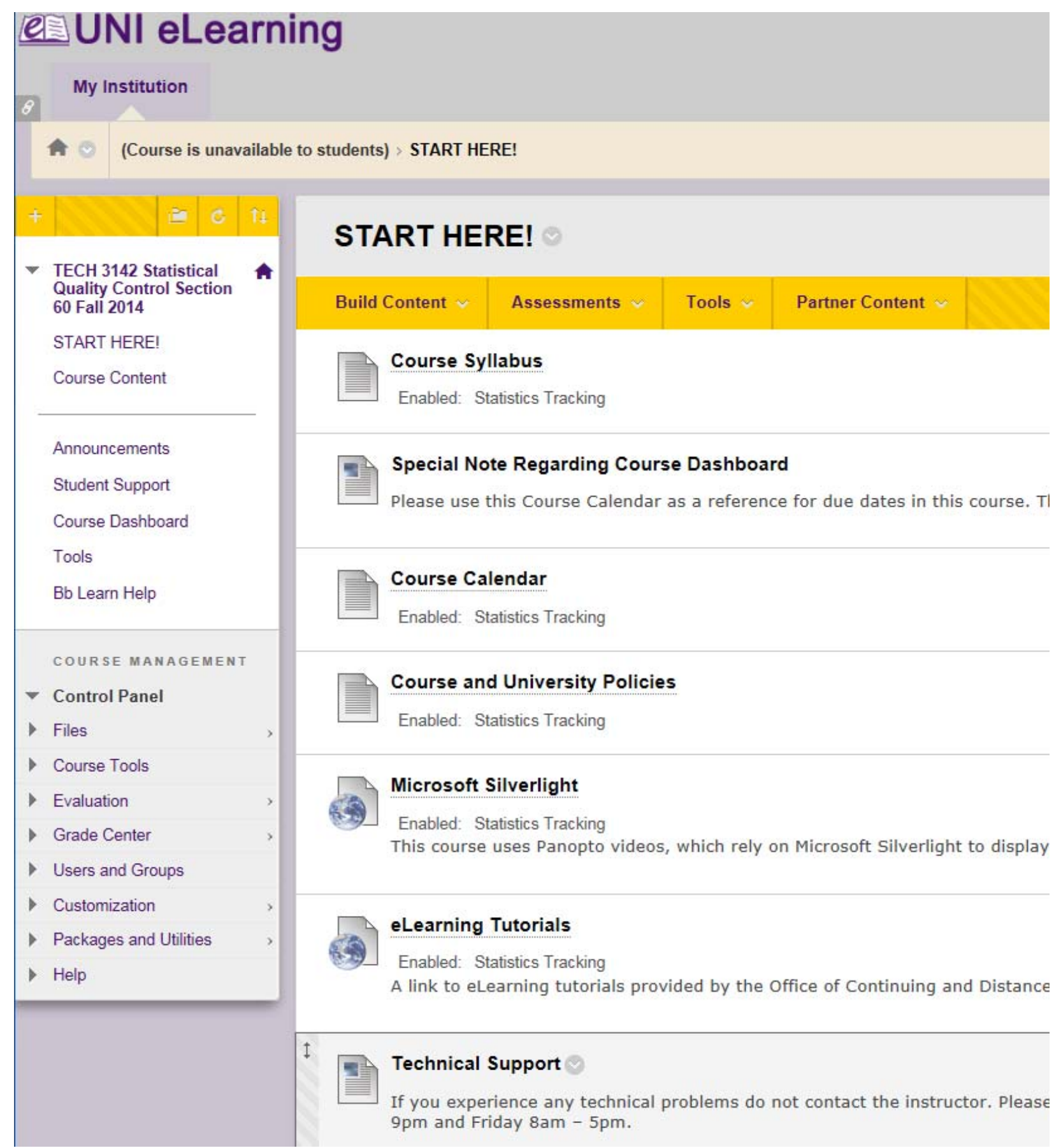

Figure 1. TECH 3142 online course interface at UNI e-learning system. 


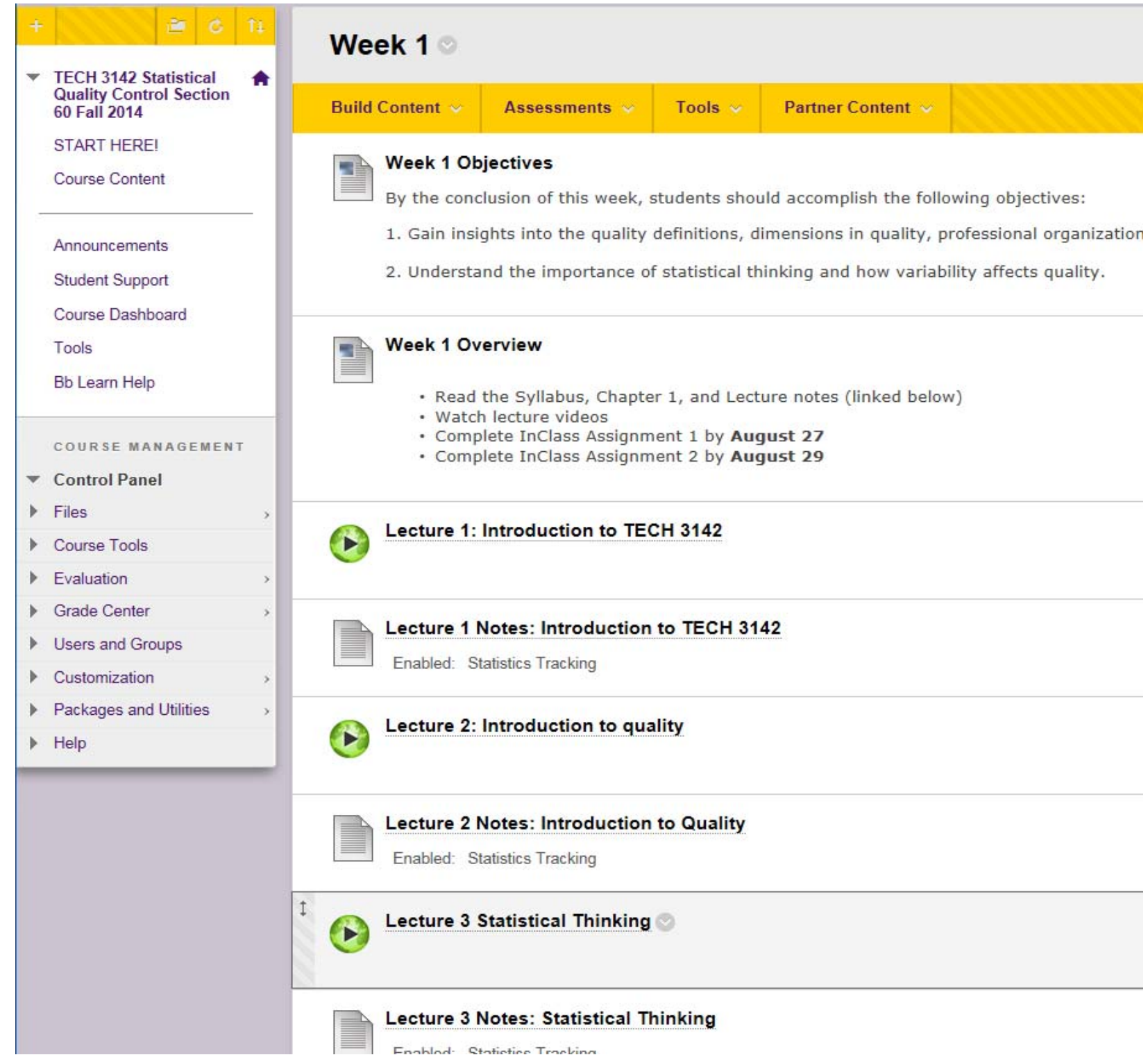

Figure 2. Screen shot of course contents in Week 1.

\section{Online Course Delivery for TECH 3142}

TECH 3142 contains many contents using math, statistics, and computer software skills in statistical analysis and data visualization. In order for TECH 3142 online course to be equivalent to a regular face-to-face class, it should include all the activities performed in the face-to-face section. This action was partially made possible with the use of technology called Panopto. Panopto is a kind of online application softwares with a campus wide license that can capture four sources - audio, video from webcam, PowerPoint, and the computer screen. Figure 3 is a screen shot of a Panopto video interface where Microsoft Excel is being demonstrated to create a Pareto chart and the quality defects in painting process for an automobile manufacturing plant are being analyzed. When the instructor is presenting, the corresponding audio and lecture slides, along with the computer screen, are packaged into lecture video files. From a student' perspective, lectures delivered in the online format were similar to the face-to-face teaching, and students can follow the Panopto video to conduct 
all activities along with the demonstration, except that no instructor was available for immediate feedback and interaction. In contrast, the students are able to pause, rewind, fast forward, or re-watch the lecture as many times as needed. This has been mentioned as an advantage by some students in the exit survey.

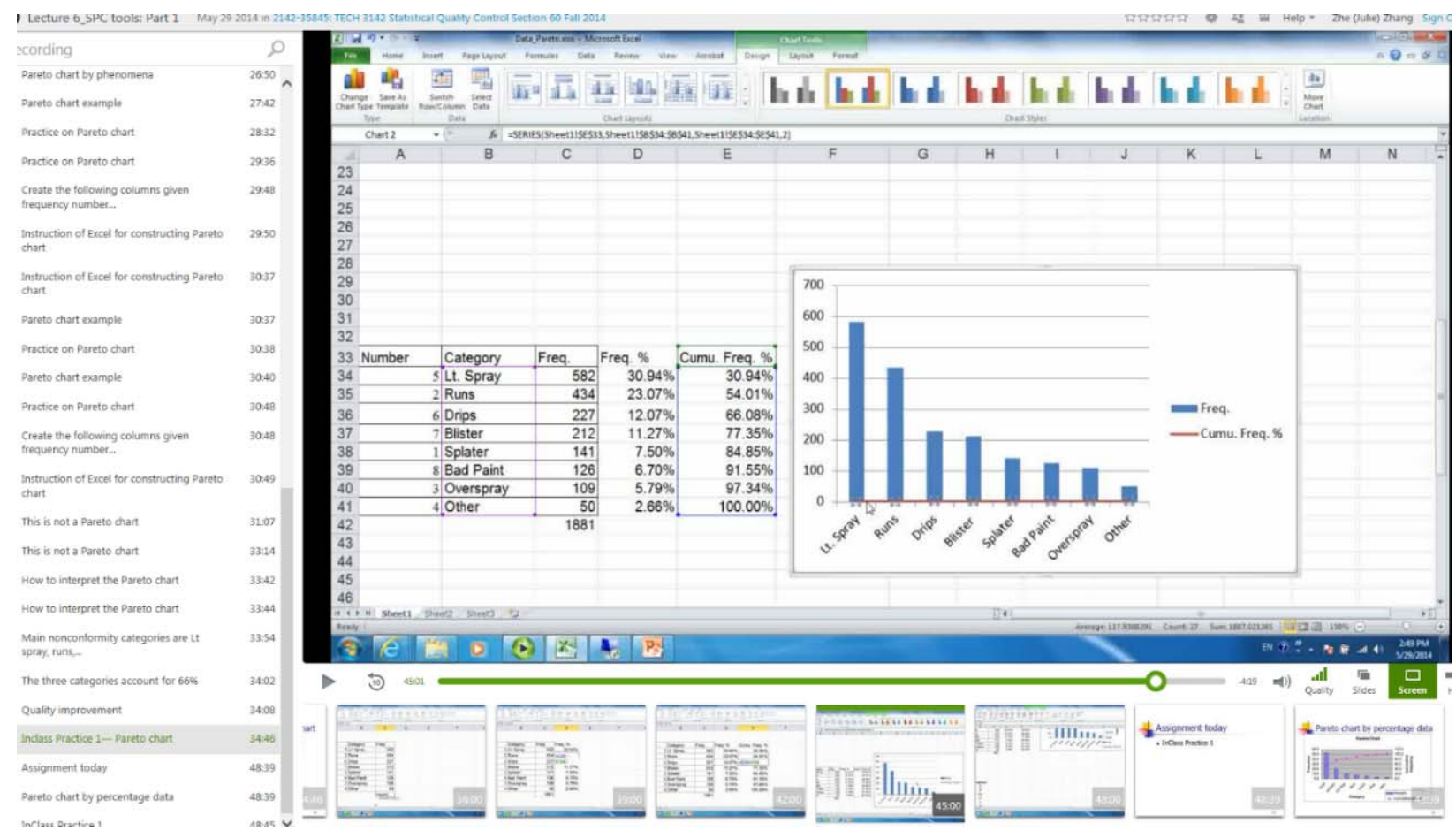

Figure 3. Interface of corded lecture captured by Panopto.

As TECH 3142 involves statistics, students cannot solidly conquer the statistical quality control concepts without assignments. Additionally, only watching the lecture video without hands-on practice, students may easily get bored or distracted. To engage students, hands-on examples of statistical analysis and data visualization using Microsoft Excel were demonstrated in TECH 3142. Students can follow the demonstration in steps to complete the instant classwork and submit it to the e-learning system as their in-class practice credit in the face-to-face format. By watching the Panopto videos that captured all instructor's class activities, students in the virtual classroom could complete the instant classwork as same as the peers in the real classroom. In total, there were 20 in-class practice assignments in the entire semester. The in-class assignments not only were designed to engage students, served as references for their weekly homework assignment, but also, in the end, were used for assessing students' learning effectiveness.

The interaction between the instructor and students is an important factor impacting student learning. The interaction can be done easily in the face-to-face situation, while the online teaching has to heavily rely on emails and phone calls. For TECH 3142 online class in Fall 2014, there were total of 102 emails in the semester. Vast majority of them were regular communications between students and the instructor, for issues regarding grades and evaluations, requests of assignment due date extension, or requests for resubmissions due to user's error. Out of the entire class of 20 students, only five students asked course topic related questions. Four students' questions were answered easily according to the principles addressed in the lecture or in the textbook. One student questioned how to apply the revised control limits of statistical process control in real world and how differently the process capabilities of variable data and attribute data were measured, which demonstrated 
his critical thinking. No student complained about the quality or clarity of the online lectures. The following is an email from a student who responded to the instructor's solicitation for input/feedback in the third week in Fall 2014 for improvement.

Hello,

In your PowerPoint, you asked if you were going too fast. I am afraid it did, mainly in the Excel presentations, as my lack of experience in Excel. If Word for that matter instead, I do feel like you go fast. Actually, it is not a major problem, because I can rewind and pause to get it.

I am enjoying this class so far, and I find the PowerPoint presentations with my notes effective.

From now on, all my submissions will be in Word format. I overlooked that in the syllabus and apologize.

Thanks!

The student performance was evaluated, including the instant in-class practice, quizzes, homework assignments, and three exams. All the in-class practices, homework problems, exam questions were exactly the same for the online course and face-to-face students. One difference is that the online students were given a timeframe of eight hours to submit the exam after they open the exam in e-learning. They were asked to use Microsoft Word to process their submission, while face-to-face students must complete and submit exams in a given time period (75 minutes for mid-term exam and 110 minutes for the final exam). Students in both sessions were allowed to use textbook, formula handouts, and other learning materials. All the problems in the exam were from the instructor's own question bank, and no existing answers can be found directly. The open book policy employed would not scarify the integrity and rigor.

\section{Assessment of Effectiveness of TECH 3142 Online Course}

TECH 3142 online course material was developed in summer 2014 and it was offered first time in Fall 2014. Using both qualitative and quantitative methods, the teaching effectiveness is compared and analyzed between two types of teaching delivery methods: TECH 3142 online in Fall 2014 and TECH 3142 face-to-face in Fall 2015. As the instructor could not enroll students randomly into the two courses, a convenient sample method is used based on the class roster, 20 and 28 enrollments in Fall 2014 and Fall 2015, respectively. The student background information collected from student background survey is displayed in Table 1. Students were able to select multiple answers and they might have left a question blank. From the background survey, it can be seen that the two groups had similar student composition, mainly junior and senior students who have already taken the prerequisite: Introduction to Statistics or Calculus.

Table 1

Student Background Information

\begin{tabular}{lll}
\hline & TECH 3142 online course & $\begin{array}{l}\text { TECH 3142 face-to-face course } \\
\text { in Fall 2015 }\end{array}$ \\
\hline Enrollment & in Fall 2014 & 28 \\
of students completed the course & 20 & 26 \\
Sophomore and others & 20 & 1 \\
Junior & 1 & 17 \\
Senior & 13 & 10 \\
Percentage of junior and senior (\%) & 6 & 96 \\
of students having taken Introduction to Statistics & 95 & 16 \\
of students having taken other math course & 17 & 10 \\
of students comfortable to use Excel & 3 & 20 \\
of students comfortable to use calculator & 16 & 28 \\
\hline
\end{tabular}


The total score of a student performance is a weighted sum, including all the assignments and tests completed in the entire semester, shown in Table 2.

Table 2

Weight Scale of Assignments and Tests

\begin{tabular}{ll}
\hline Category & Weight (\%) \\
\hline Quiz (3) \& in-class practice (20) & 15 \\
Homework (10) & 20 \\
Exam 1 & 20 \\
Exam 2 & 20 \\
Final exam & 25 \\
\hline
\end{tabular}

For each of the five categories in Table 2, $t$-test is conducted to compare the two group samples means in terms of hypothesis test as:

$$
\begin{gathered}
\text { Ho: } \mu_{1}=\mu_{2} \\
\text { Ha: } \mu_{1} \neq \mu_{2}
\end{gathered}
$$

The $t$-test of two samples means assuming equal variance. The summarization of the $t$-test results output by Excel for the five categories are listed in Table 3. All 20 students completed the online course in Fall 2014, but two students dropped out in the middle of Fall 2015. The $t$-test excluded these two students' scores to provide a fair comparison, resulting in the degree of freedom for $t$ distribution of 44 . Using a significant level of $p<0.05$, it can be concluded that there are no significant differences in the student performance between the students in online or face-to-face courses, because all the probability values in Table 3 are larger than the pre-determined significant level $(p>0.05)$. Referring to Table 3 , it is noticed that variances for the two group sample data are within the range of $\frac{\text { Variance }_{1}}{\text { Variance }_{2}} \leq 2$ for Homework, Exam 1, Exam 2, Exam 3, and Total. However, the variance ratio for Quiz \& In-Class practice violates this assumption $\left(\frac{\text { Variance }_{1}}{\text { Variance }_{2}}=\frac{5.66672}{0.784322}>2\right)$. As this category contributed the lowest portion to the overall performance evaluation, this violation is neglected in the comparison.

Table 3

T-Test of Student Performance for the Two Teaching Methods

\begin{tabular}{llcc}
\hline Performance & Statistics & Fall 2014 online course & Fall 2015 face-to-face course \\
\hline \multirow{4}{*}{ Quiz \& in-class practices } & Mean & 13.29973 & 13.36683 \\
& Variance & 5.66672 & 0.784322 \\
& $t$ statistics & -0.13264 & \\
& $p(T \leq t)$ two-tail & 0.8950 & 16.96859 \\
Homework & Mean & 15.55667 & 7.358629 \\
& Variance & 11.39472 & \\
\hline & $t$ statistics & -1.57354 & 15.10907 \\
Exam 1 & $p(T \leq t)$ two-tail & 0.122758 & 8.431825 \\
& Mean & 16.45 & \\
\hline
\end{tabular}


(Table 3 to be continued)

\begin{tabular}{llcc}
\hline & Mean & 14.6 & 13.60769 \\
Exam 2 & Variance & 21.32865 & 19.38821 \\
& $t$ statistics & 0.966123 & \\
\hline & $p(T \leq t)$ two-tail & 0.339563 & 18 \\
Exam 3 & Mean & 19.03125 & 13.985 \\
& Variance & 22.04914 & \\
\hline & $t$ statistics & 0.829611 & \\
Total score & $p(T \leq t)$ two-tail & 0.411237 & 76.75218 \\
& Mean & 78.93765 & 142.6849 \\
& Variance & 217.5148 & \\
\hline
\end{tabular}

Another assumption of $t$-test is that the sample data should follow normal distribution. A normal quantile plot can visualize the extent to which the variable is normally distributed. If a variable follows a normal distribution, the normal quantile plot approximates a diagonal straight line. To ensure that the assumption of normality was valid, a normal quantile plot for the total scores of two groups are constructed to show the data distribution in Figure 4 without checking the normal distribution assumption for each individual category, because the total score represented the overall student performance. Although the two sample data do not display a perfect diagonal straight line (normal distribution), the data points are clustered around the diagonal straight line within the boundary. Thus, the normal assumption for $t$-test is approximately held.

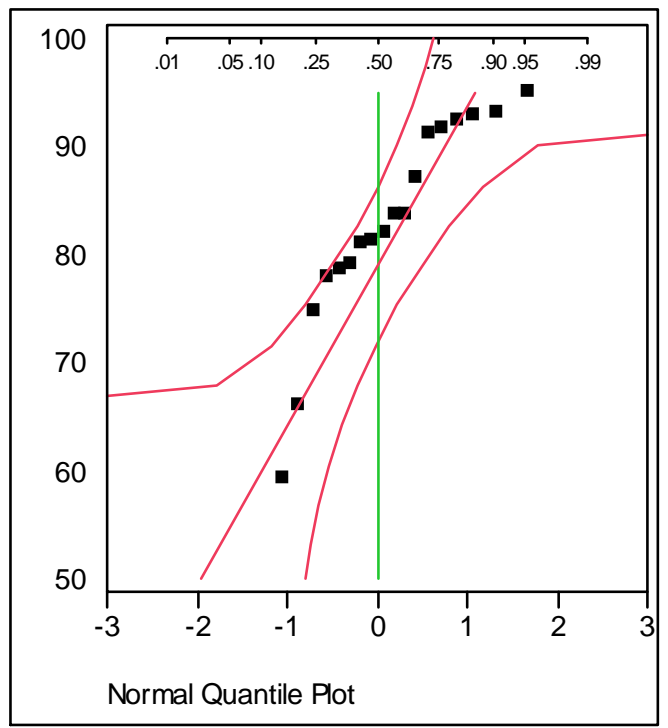

(a) Online course

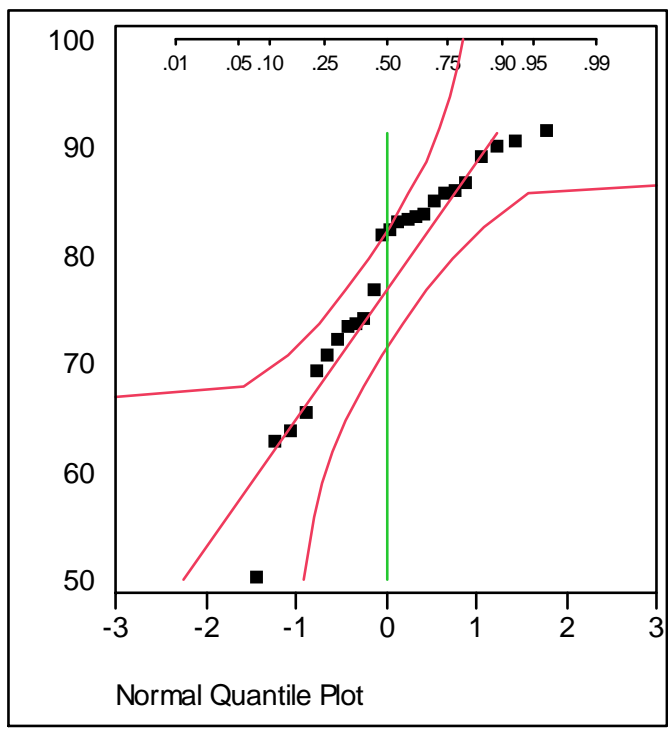

(b) Face-to-face course

Figure 4. Normal quantile plot of student total score.

\section{Reflections and Conclusions}

This paper presents a case study on the development, implementation, and effectiveness assessment of an online course that contains intensive contents in math and statistics calculation, data analysis, visualization, and interpretation. In addition, computation software (Microsoft Excel) chart operation and demonstration were also 
intensively used in the course. Using the convenient sample method and $t$-test, student performances were compared to the same course (TECH 3142) offered in Fall 2014 online and face-to-face in Fall 2015 with the same instructor. All $t$-tests conducted in both individual performance category and the total score performance showed no significant differences $(p>0.05)$ for the student performance when the course was offered online or face-to-face.

The course sets apart from many other online courses by containing math, statistical contents, and problem solving assignments. The key factor that makes TECH 3142 successfully equivalent to its face-to-face version was the use of the e-learning system, the design approach using QM standards, and the use of Panoptoto capture lectures. Without Panopto Recorder, it would have been hard to deliver an online course, such as TECH 3142. The feedback from the optional student exit survey showed that, for most students, this was the first time that they viewed lectures captured via Panopto. They felt it was easy to use, and most of them strongly agreed that Panopto videos helped their learning significantly.

Reflection from the instructor viewpoint suggested that the professional development opportunity for faculty and the institutional support received from on campus are vital. Although Panopto is user-friendly application software, basic training through a workshop in one to two hours is needed to learn the most commonly used features, such as how to capture videos, how to adjust resolutions to make better quality for the web interface, and how to deploy the videos in the right spot in the e-learning course. The support from the instructional design team provided valuable suggestions and made the course delivery and student learning and assessment in a valid and systematic approach. The Continuing and Distance Education team provided all technical supports from uploading the course materials in the e-learning system to computer and network software configuration in a timely manner when the instructor or students sought help. For all online courses offered through the Continuing and Distance Education, it is the team, not the instructor, who takes the responsibility to provide technical support to students. This policy greatly reduces instructors' workload in diagnosing individual technology problems that students may face with using different devices to access the course. The faculty, then, can fully concentrate on the subject and the content.

Interaction between the instructor and students is not synchronized for this online course. Comparing with the face-to-face teaching format, it may be viewed as a disadvantage. To overcome the drawback, the instructor in this online course needed to respond to all emails, phone calls, voice mail messages in a timely manner to make sure that prompt communication is being practiced. Email was the primary communication in TECH 3142 online course. The official policy set up in the course syllabus was that the instructor must get back to student inquiries within 48 hours. As a matter of fact, questions were answered through email immediately or within eight hours after the instructor viewed them, if the instructor was handling other high priority duties. Email was effective for explaining course administration questions, such as class policies and assignment due time, but not necessarily for addressing content-related questions. The instructor recently has been introduced ZOOM by the Educational Technology team. ZOOM is a web-based free application that can easily set up online meetings. Using ZOOM's online meetings, the instructor was able to share her computer screen for computer demonstrations. The ZOOM technology can compensate for the drawback of online course.

Detailed examination of Table 3 found that for all three exams, online students obtained higher scores than the face-to-face students, though the differences were not statistically significant. However, the homework and in-class practices showed an opposite trend. This reverse correlation between homework practices and exams may indicate exam timeframe for the online course was not as strict as the face-to-face course. In the 
face-to-face format, all students manually wrote their answers in the exam sheets and used hand-held calculators for calculation problems. They must complete the exam within a class period 75 minutes for mid-term exam and 110 minutes for final exam. The online students had to process exam submission files in Microsoft Word. In case that they encountered computer problems, they were allowed longer time for the exams. To make the two teaching format even similar in the future, online students' exam timeframe will be made same as the face-to-face teaching. If students feel the given timeframe using Microsoft Word is not sufficient, students can print the exam questions, manually write the answers, scan the completed exams as PDF file, and submit to e-learning.

Industries' demand for sufficiently trained engineers and technologists is increasing to remain competitive in manufacturing globalization. The development of educational technologies powered by high-speed computers and computer networks has enabled many universities to offer online and hybrid courses/degree programs, in addition to the traditional face-to-face instruction method, to accommodate the educational needs. With technologies growing more in artificial intelligence, virtual reality, computer simulation, networking, teleconferencing and online meeting, the dissimilarities of teaching and content delivery in online and face-to-face courses will become smaller and smaller. The courses having intensive technical contents can be taught in distance learning without sacrificing quality and teaching effectiveness.

\section{References}

Affordable College Online. (2015). Best online colleges. Retrieved May 18, 2015, from http://www.affordablecollegesonline.org/ best-colleges-online/

Aichouni, M., Benchicou, S., \& Nehari, D. (2013). Knowledge management through the e-learning approach-A case study of online engineering courses. European Journal of Engineering Education, 38(3), 316-328.

Allen, I. E., \& Seaman, J. (2014). Grade change-Tracking online education in the United States. Retrieved May 18, 2016, from http://www.onlinelearningsurvey.com/reports/gradechange.pdf

Astatke, Y., Scott, C. J., Connor, K. A., \& Ladeji-Osias, J. O. (2012). Electric circuits online-Online delivery of electrical engineering laboratory courses. ASEE Annual Conference Proceedings, San Antonio, T.X., USA.

Bourne, J., Harris, D., \& Mayadas, F. (2005). Online engineering education: Learning anywhere, anytime. Journal of Engineering Education, 94(1), 131-146.

Caruth, G. D., \& Caruth, D. L. (2013). Distance education in the United States: From corresponding courses to the Internet. Turkish Online Journal of Distance Education, 14(2), 141-149.

Goodson, C. E., Miertschin, S. L., \& Stewart, B. (2011). Distance delivery of courses: What components are important to students? ASEE Annual Conference Proceedings, Vancouver, B.C., Canada.

Hart, C., Friedmann, E., \& Hill, M. (2015, April 16-20). Online course-taking and student outcomes in California community colleges. American Educational Research Association Annual Meeting, Chicago, I.L., USA. Retrieved May 18, 2016, from http://www.aera.net/Newsroom/RecentAERAResearch/OnlineCourse-TakingandStudentOutcomesinCaliforniaCommunityC olleges/tabid/15916/Default.aspx

Kinney, L., Liu, M., \& Thornton, M. A. (2012). Faculty and student perceptions of online learning in engineering education. ASEE Annual Conference Proceedings, San Antonio, T.X., USA.

Peerani, N. (2013). Barriers to distance learning: The educator's viewpoint. Distance Learning, 10(2), 29-33.

Quality Matters. (2015). Course design rubrics standars. Retrieved May 18, 2016, from https://www.qualitymatters.org/qaresources/rubric-standards/higher-ed-rubric

Ralston-Berg, P. (2014). Student perspectives of quality: Value of QM rubric items. Internet Learning, 3(1), 117-126.

Stack, S. (2015). Learning outcomes in an online vs. traditional course. International Journal for the Scholarship of Teaching and Learning, 9(1), 1-18.

Stassen, M., Blaustein, M., Rogers, R., \& Shih, M. Y. (2007). Undergraduate student outcomes: A comparison of online and face-to-face courses. Retrieved May 18, 2016, from http:/www.umass.edu/oapa/oapa/publications/misc_docs/undergradstudent-outcomes.pdf 
United News of India (UNI) Continuing and Distance Education. (2016). Rankings and honors. Retrieved May 18, 2016, from https://uni.edu/continuinged/about-us

The U.S. Department of Labor. (2010). Advanced manufacturing industry-Addressing the workforce challenges of america's advanced manufacturing workforce. Retrieved May 18, 2016, from http://www.doleta.gov/BRG/pdf/Advanced\%20Manufact uring\%20Report\%2011.1.05.pdf

Welsh, E. T., Wanberg, C. R., Brown, K. G., \& Simmering, M. J. (2003). E-learning: Emerging uses, empirical results, and future direction. International Journal of Training and Development, 7(4), 245-258.

$\mathrm{Xu}, \mathrm{D} ., \quad \&$ Jaggars, S. S. (2011). The effectiveness of distance education across virginia's community colleges: Evidence from introductory college-level math and english courses. Educational Evaluation and Policy Analysis, 33(3), 360-377.

$\mathrm{Xu}, \mathrm{D}$., \& Jaggars, S. S. (2013). The impact of online learning on students' course outcomes: Evidence from a large community and technical college system. Economics of Education Review, 37, 46-57.

$\mathrm{Xu}$, D., \& Jaggars, S. S. (2014). Performance gaps between online and face-to-face courses: Differences across types of students and academic subject areas. Journal of Higher Education, 85(5), 633-659.

Young, M. R. (2014). Integrating quality matters into hybrid course design: A Principles of marketing case study. Journal of Marketing Education, 36(3), 233-243. 